\title{
The effect of organizational justice and social interdependence on knowledge sharing
}

\begin{abstract}
Knowledge hoarding in Requirements Elicitation (RE) phase could lead to Information Systems Development (ISD) project failure. Many researchers have discussed important factors in knowledge sharing. Nevertheless, the success rate for ISD projects is low and there are other major factors for consideration. Review was conducted to identify potential gaps in existing literature and to explore new factors that impact ISD knowledge sharing in RE. Based on systematic review of literature, two new factors are identified namely Organizational Justice and Social Interdependence. The success of ISD projects are impacted by organizational justice and social interdependence. The proposed theoretical model provides project managers a new platform to further understand ISD knowledge sharing between business users and external IT professionals in RE.
\end{abstract}

Keyword: Knowledge sharing; Information systems development; Reasoned action; Organizational Justice; Social interdependence 